\title{
أنهاط تعرض الشباب الجامعي للمواد السمعية البصرية الإخبارية وعلاقته بمستوي الوعي السياسي لديهم"
}

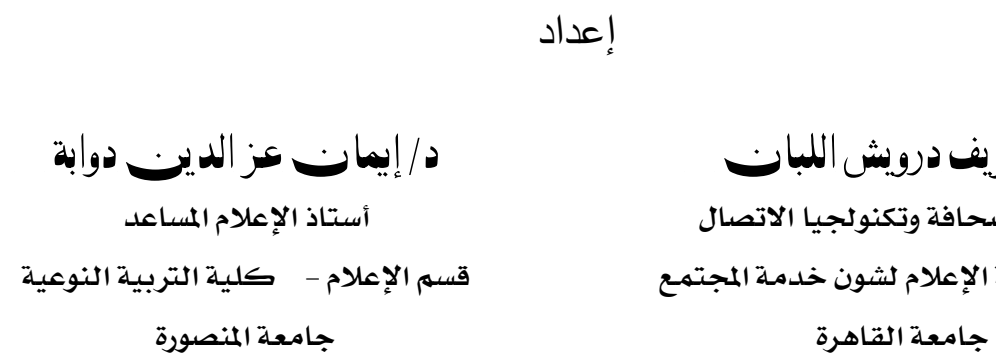

د/إيمار عز الديرن دوابة أستاذ الإعلام المساعد

قسم الإعلام - كلية التربية النوعية المعاعدامية

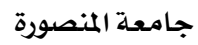

جامعة القاهرة

أ/ سالحــ محمد صالح محمد

$$
\text { باحسثة ماجستير }
$$

مجلة بحوث التربية النوعية ـ جامعة المنصورة

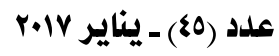




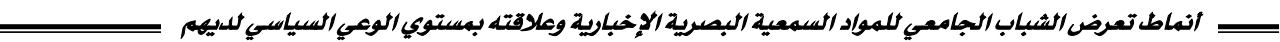


مجلة بحوث التربية النوعية - عدد 0؛ - يناير r. r.

\section{أنهاط تعرض الشباب الباهمي للمهاد السمهية البصرية الإخبارية \\ وعلاقته بمستوي الوكي السياسي لديهميم}

إعداد

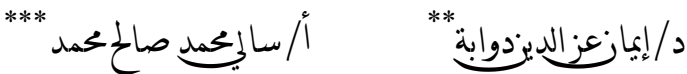

أد/شريف درويشاللبان* - ت

مقدمهة

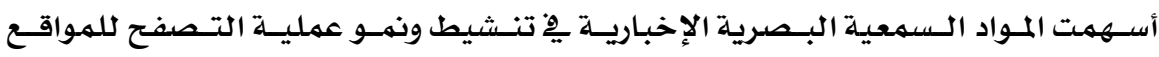

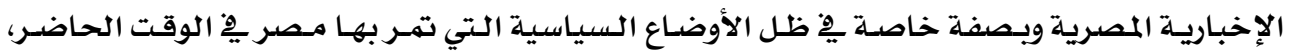

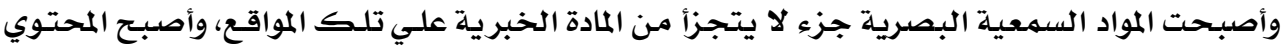

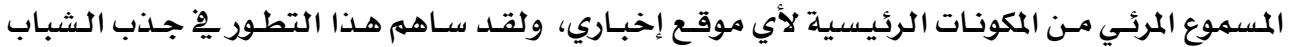

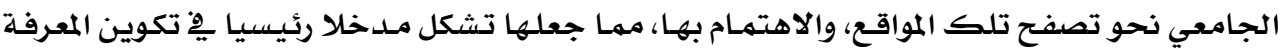

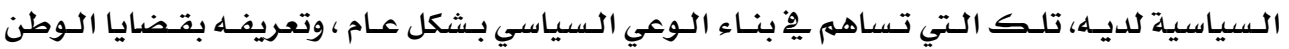

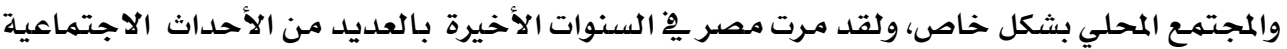

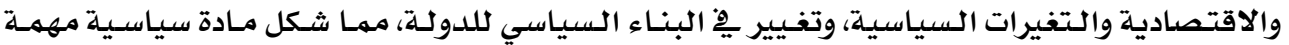

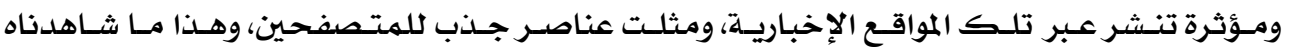

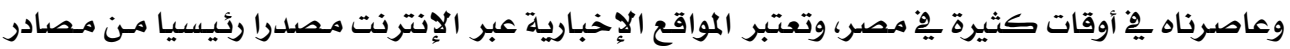

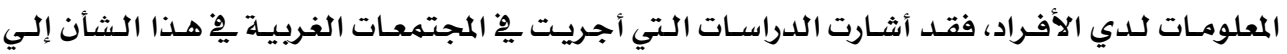

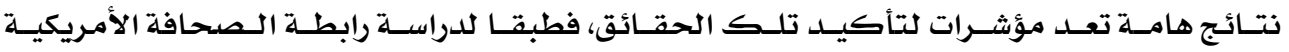
Newspaper Association of America

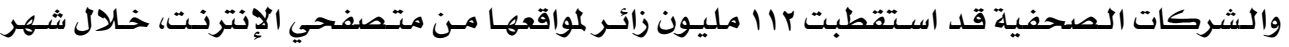

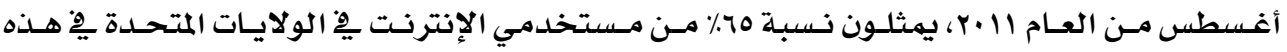

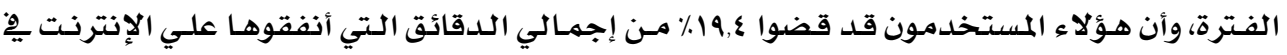

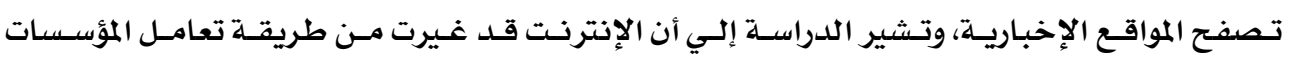

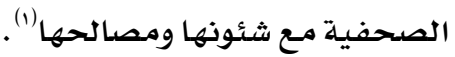

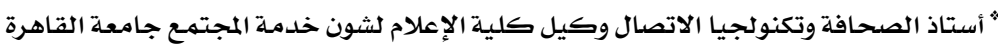

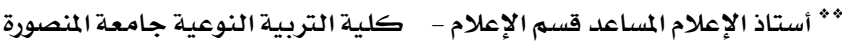

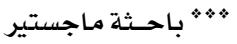

$\left.{ }^{1}\right)$ Chung Joo Chung,Yoonjae Nam, Michael A. Stafonone, (2012), Exploring Online News Credibility: The Relative Influence of Traditional and Technological Factors, journal of computer Mediated Communication, Vol. 17, pp: 171-186. 


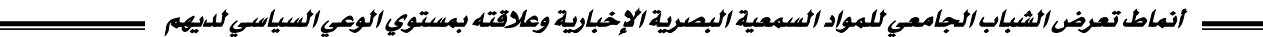

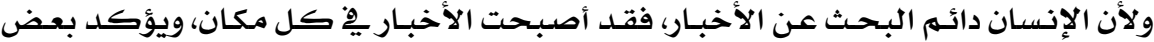

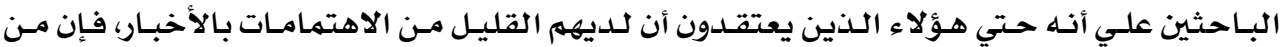

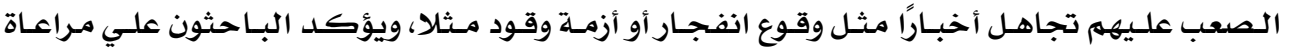

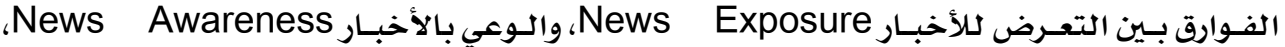

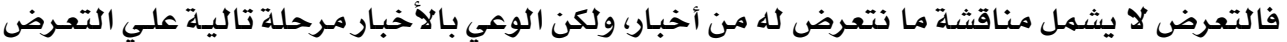

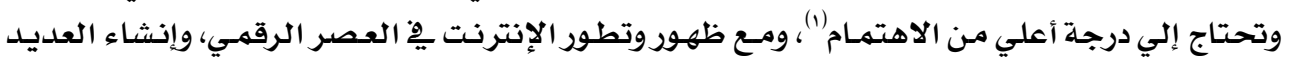

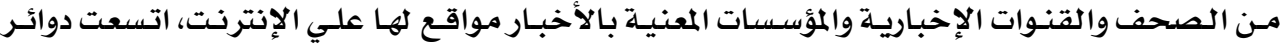

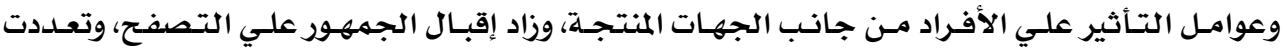

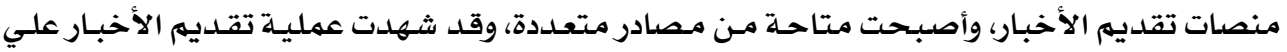

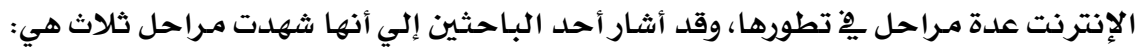
• المرحلـة الأولـي: وهـي إعـادة إنتـاج المحتـوي الـورقي التقليـدي للـصحيفة المطبوعـة بخـصـائص

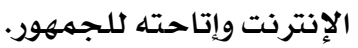

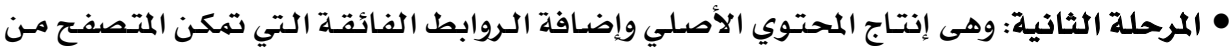

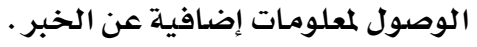

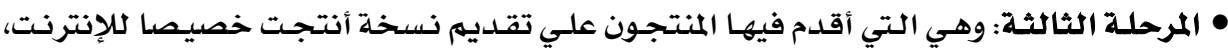

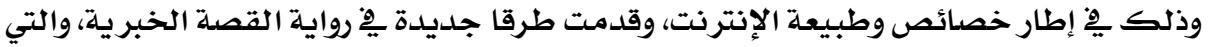

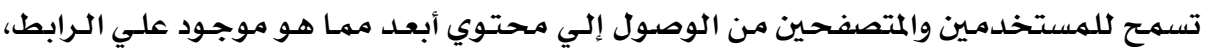

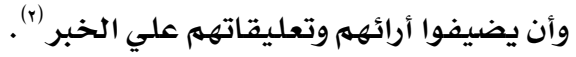

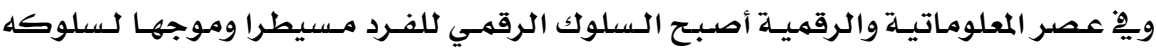

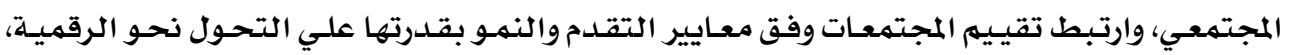

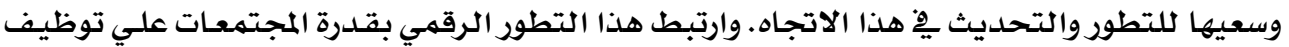

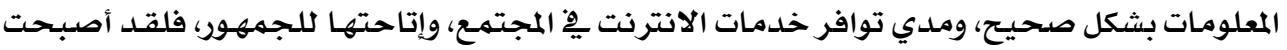

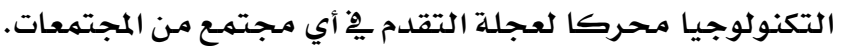

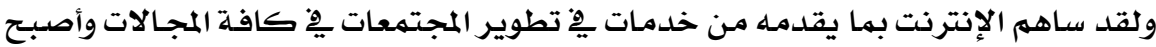

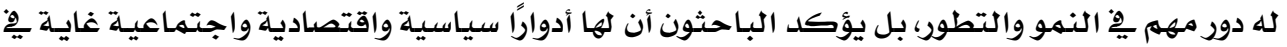

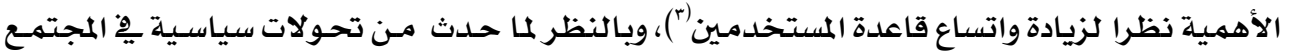

$\left.{ }^{1}\right)$ James Klurfeld\& Howard Shneider (2014), News Literact: Teaching the internet Generation to make reliable Information Choice, Center for Effective Publication management, Brookings. June 2014.

$\left.{ }^{2}\right)$ Chung Joo Chung, Yoonjae Nam, Michael A. Stafonone, (2012), Exploring Online News Credibility: The Relative Influence of Traditional and Technological Factors, op cit.

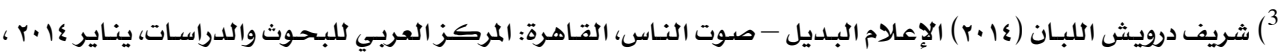

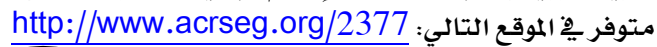




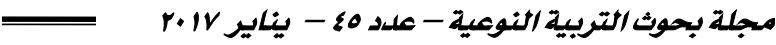

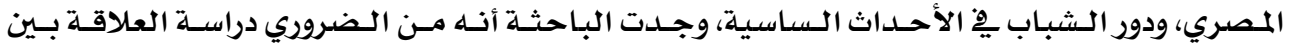
التعرض للهواد السمعية البصريـة الإخباريـة والوعي السيـاسي لدي الشبـاب الجامعي.

هـش مالة البصث

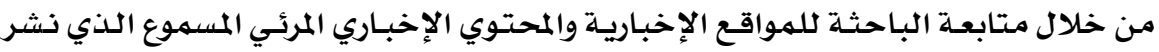

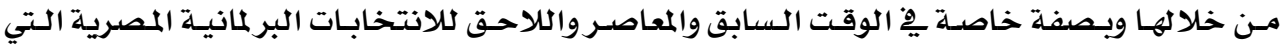

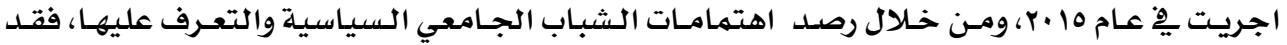

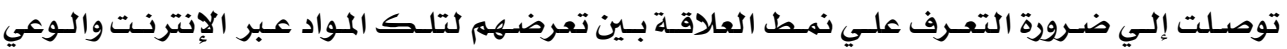

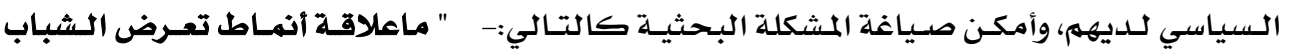

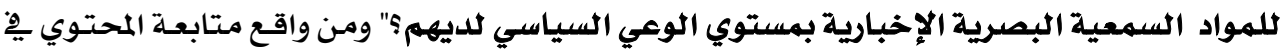

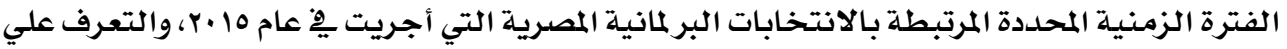

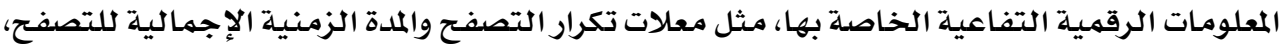

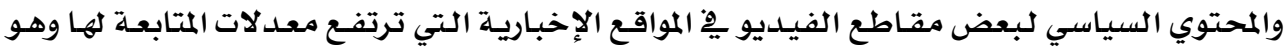

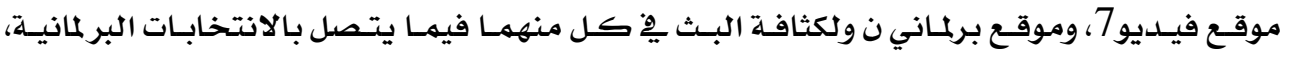

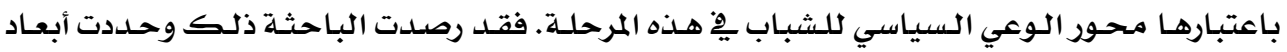

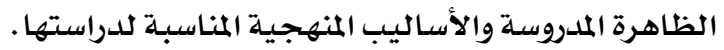

أهد|ف البحث

$$
\text { يهدف هذا البحث إلي:- }
$$

ا ـ التعرف علي مستوي متابعة الشباب الجامعي عينة الدراسـة للمواقع الإخبارية بشكل عام.

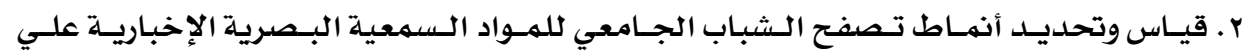

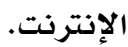

r. التعـرف علـي مستوى متابعـة الـشباب الجـامعي للهـواد السمعية البـصرية الإخباريـة ( محسل الدراسة) والمرتبطة بالوعي السياسي.

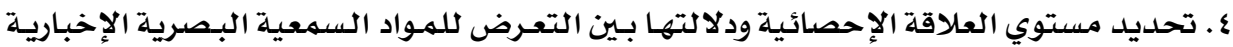
والوعي السياسي لدي الشباب. أهمينة البحث.

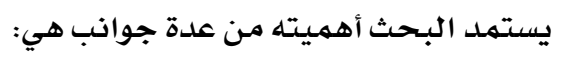

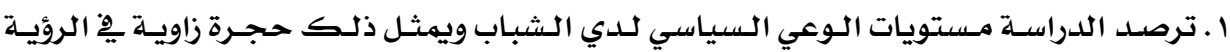

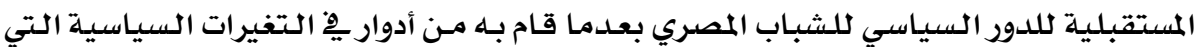

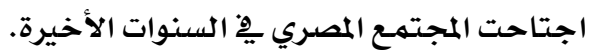

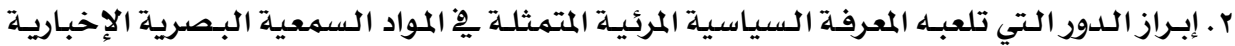

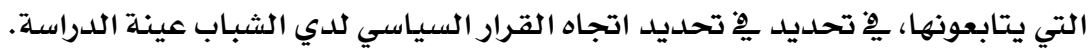


r. ريط الممارسات السياسية الفعلية القائمة أو الأدوار السياسية المتوقعة من الشباب عينة الدراسة

بمستوي متابعتهم لوسائل الإعلام والمواد السمعية البصرية البهاتية عبر المواقع الإخبارية.

\section{الدراسات السابقة:}

مـن خـلال متابعـة الباحثـة للمحساور الرئيسية المرتبطـة بـالمواد السمعية البصرية الإخباريـة

علي الإنترنت وتأثيراتها المعرفية والإدراكية علي المتصفحين من الجمهور، فإنه يمكن رصد الدراسـات

الاتية التي ترتبط بمجال الدراسلة.

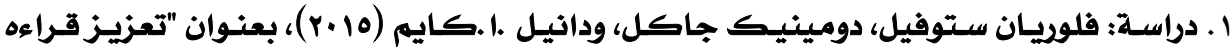

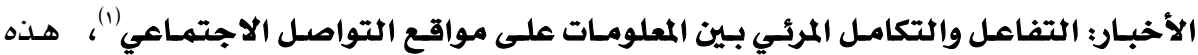

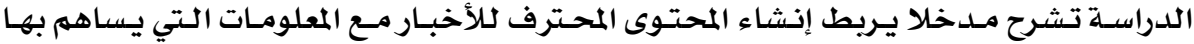

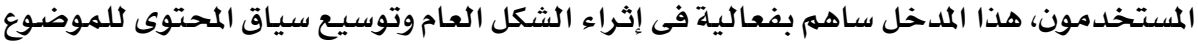

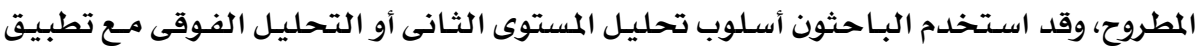

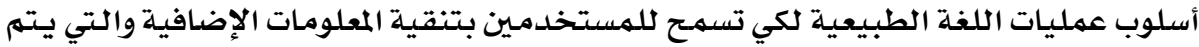

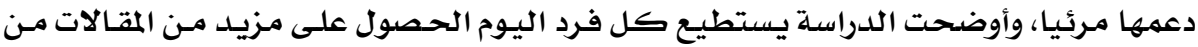

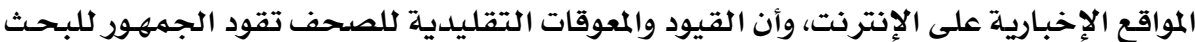

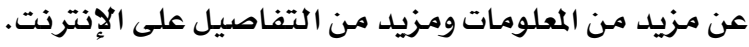

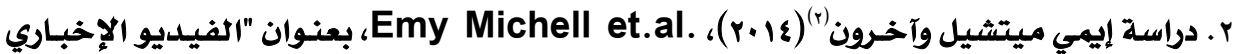

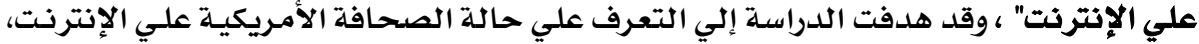

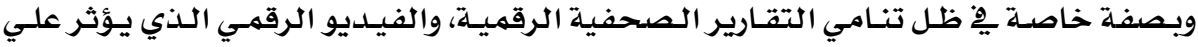

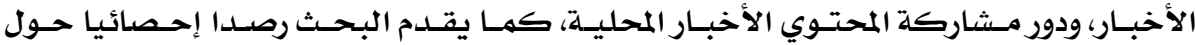

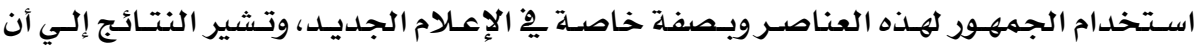

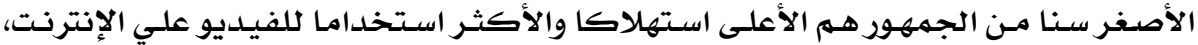

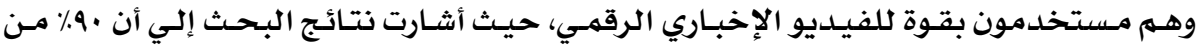

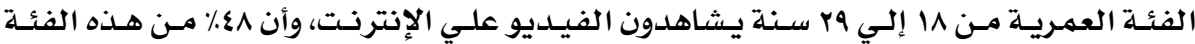

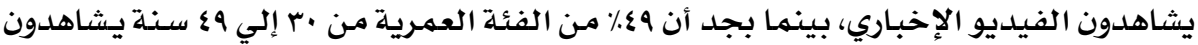

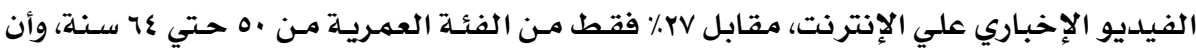

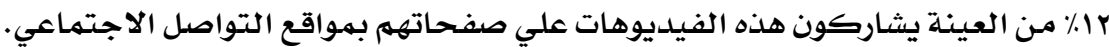

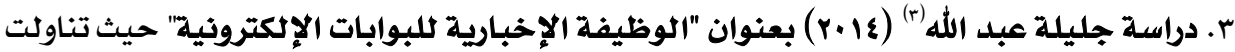

$\left.{ }^{1}\right)$ Flowrian stofeel et al. (2015), Visual interactive and integrated information on the social media" journal of media research vol. 22 no $1 \mathrm{p}: 224-238$.

$\left.{ }^{2}\right)$ Emy Michell et al (2014), News video on the web A Growing, if Uncertain, Part of News.", Pew Research center, available at: www. pewresearch.org 3) جليلة عبد الله خلف ( ( r)، الوظيفة الإخبارية للبوابات الإلكترونية - بحث منشور (الشارقة: دار الكتاب الجامعي). 


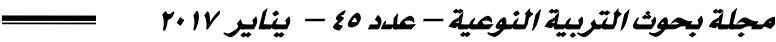

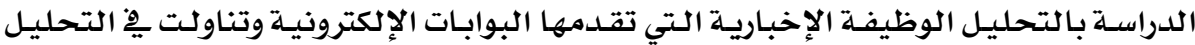

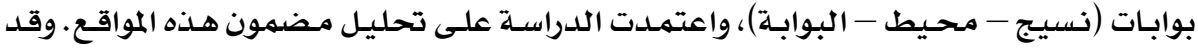

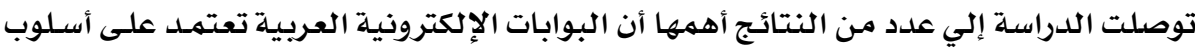

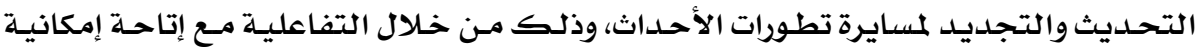
المشاركة يِّ إبداء الرأي والتعليق على المضمون المقدم بها. ع. دراسة ثريف درويش اللبان(1) (1 +r)، بعنوان: (الضوابط المهنية والأخلاقية والقانونية للإعلام

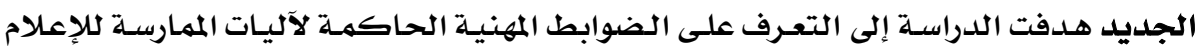

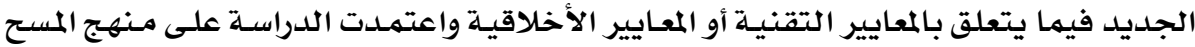

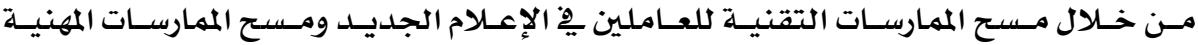

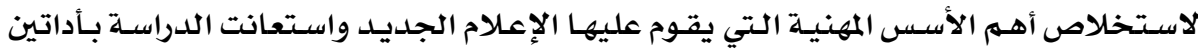

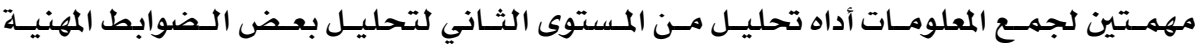

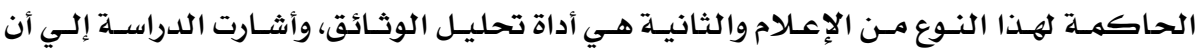

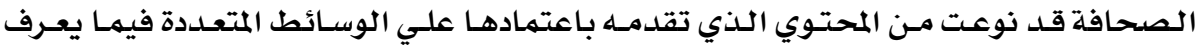

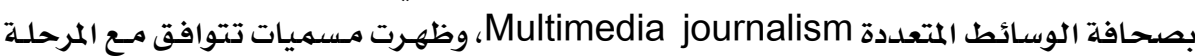

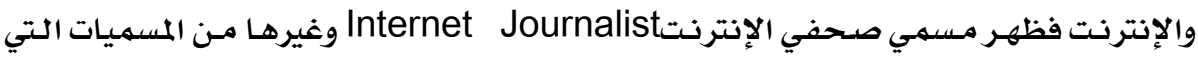

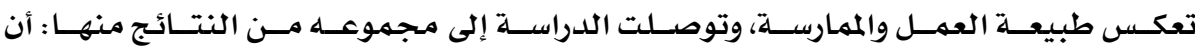

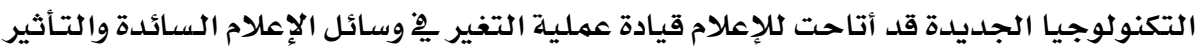

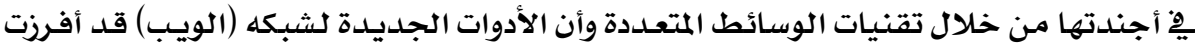

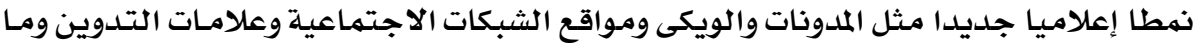
يسمى بصحافه المواطن.

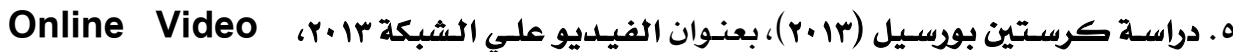
2013.

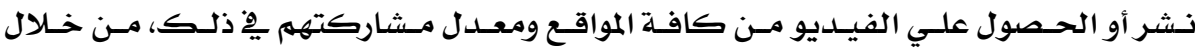

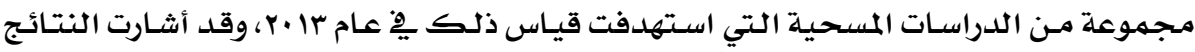

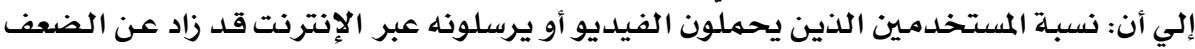

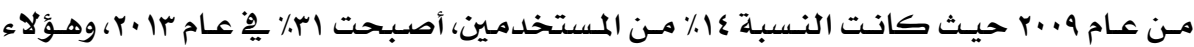

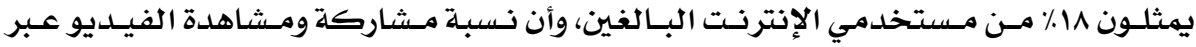

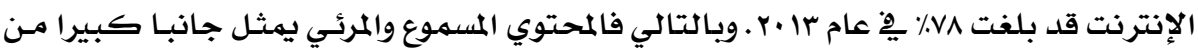

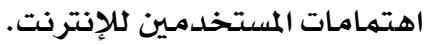

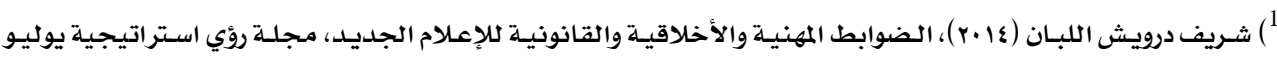
.1ro- 99 : 18 r.

$\left.{ }^{2}\right)$ Kristen Purcell, (2013), Online Video 2013, Pew Research Center, available at: http://pewinternet.org. 

T. دراسـة: تشونج جـو تشونج وآخـرون Chung joo Chung et al (r. (r) (1)، بعنـوان:

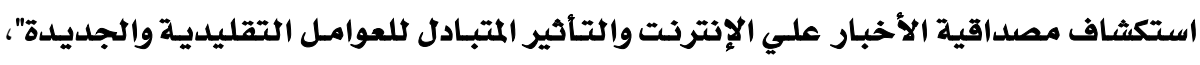

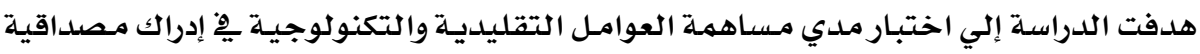

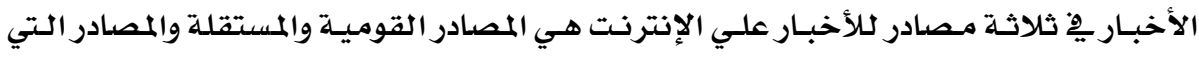

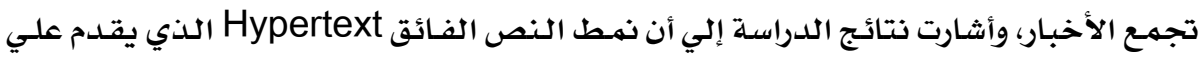

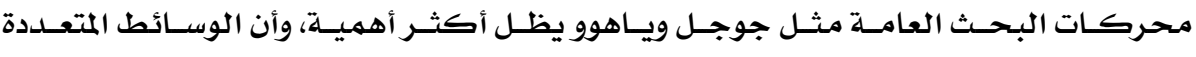

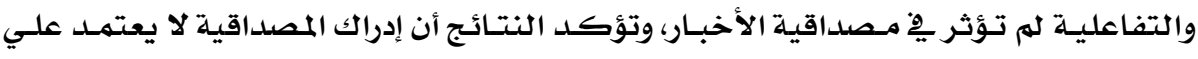

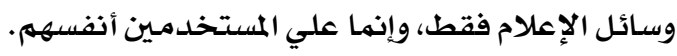

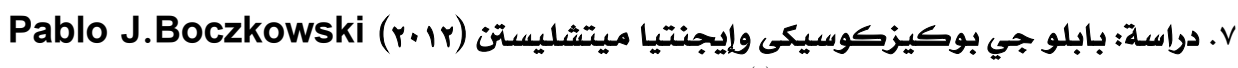
\& Engenia Mitchelstion

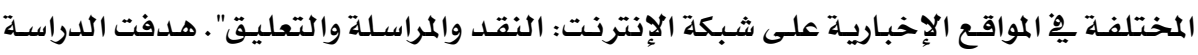

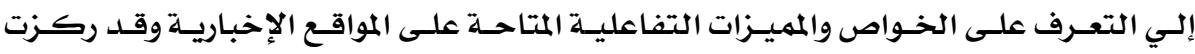

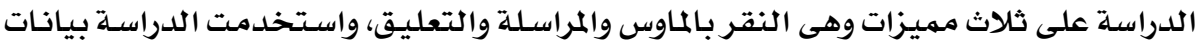

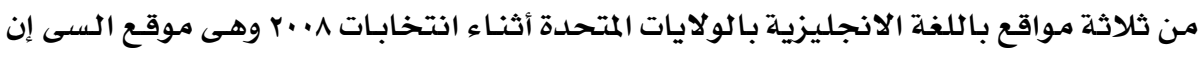

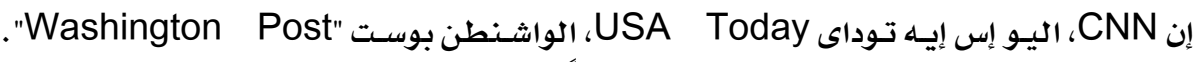

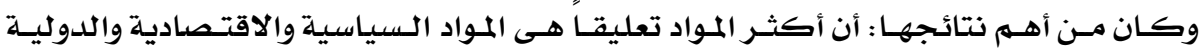

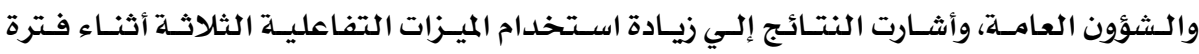

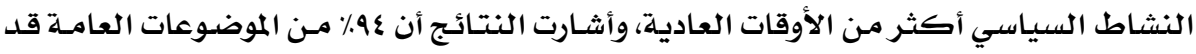

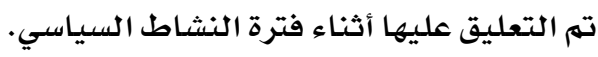

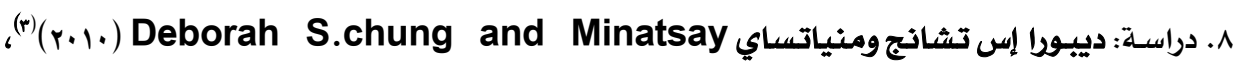
بعنوان: "التقديم التفاعلي للأخباروتأثيراته على تقييم الإدراك : أقرب إلى إلى الأخبار الأفضل \&

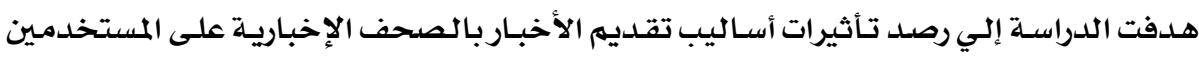

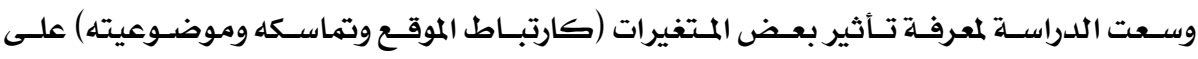

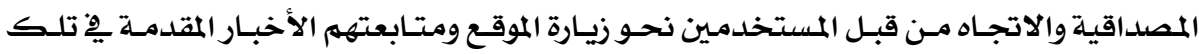

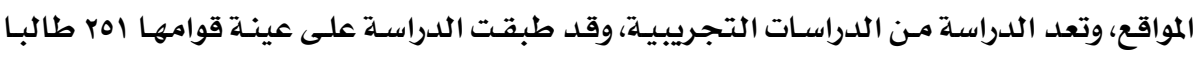

$\left.{ }^{1}\right)$ Chung Joo Chung, Yoonjae Nam, Michael A. Stafonone, (2012), Exploring Online News Credibility: The Relative Influence of Traditional and Technological Factors" op cit.

$\left.{ }^{2}\right)$ Pablo J.Boczkowski and Eugenia mitchelstein. "How user take advantage of different forms of internet activity on line news sites: clicking emailing and commerce.

$\left.{ }^{3}\right)$ Debura s. Chung,\& Mina Tsay,( 2010), Interactive News Presentation and it's Effects on Evaluation Perception: is being "closer" to the news better? ,Paper submitted to the newspaper Division of Association for Education in Journalism and Mass communication, (Boston,5-8 August 2010. 
ب مجلة بحوث التربية النوعية - علد 0؛ - بيناير r.lV

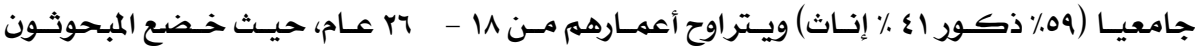

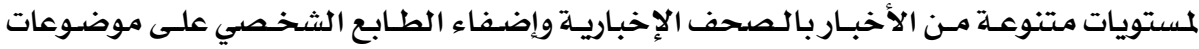

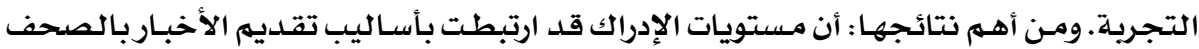

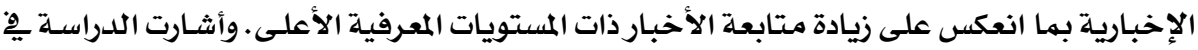

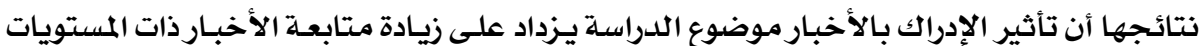

$$
\text { الأعلى. نوانَ. }
$$

9. دراسة وي كوي وآخرون (2010) Wei Qi, et al. بعنوان: "تحليل متكامل النص والفيديو

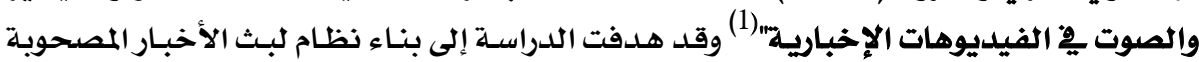

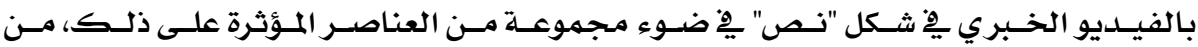

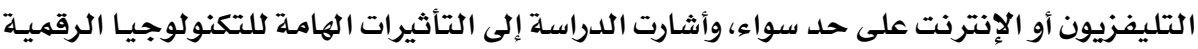

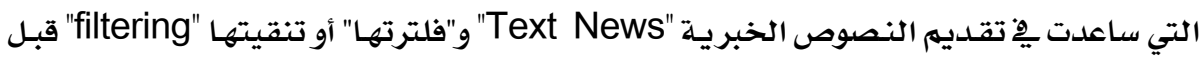

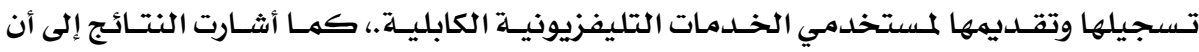

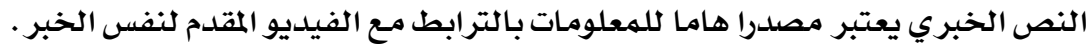

\section{- تعقيب علي الدراسات السابقة.}

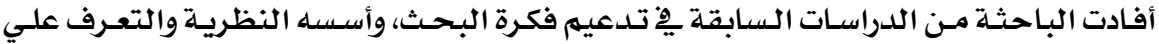

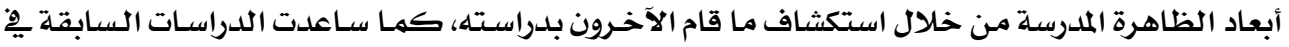

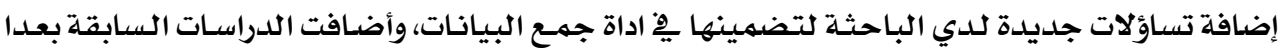

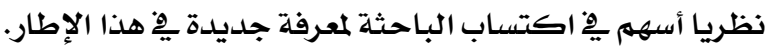

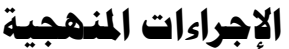

\section{فروض البحث:}

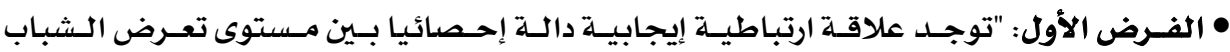

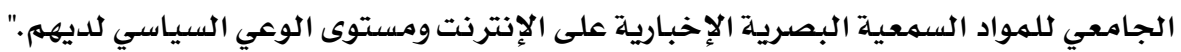

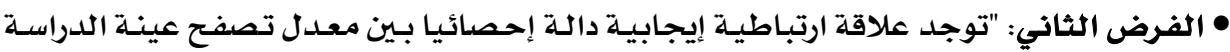

\section{لكلإنترنت، ومعدلات تصفح ومتابعة المواقع الإخبارية".}

1. اجتمع وعينة البحث:

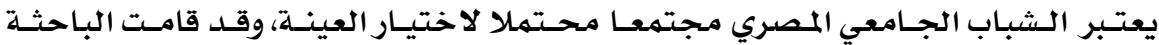

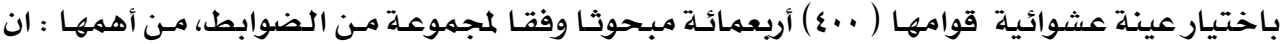

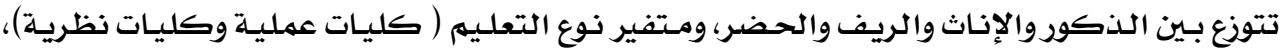
وجامعة إقليمية وجامعة مركزية، ووقع الاختيار علي جامعتي القاهرة والمنصورة.

$\left.{ }^{1}\right)$ Wei Qi, et al. (2010), Integrating Visual, Audio and text Analysis for News Video, available at; http://www.ieee.org/. 
عبد أنهاط تعرض الشباب الجامعي للمواد السمعية البصرية الإخبارية وعلاقته بهستوي الوعي السياسي للديهم ل r r أدوات البحث والمعالجة الإحصائية:

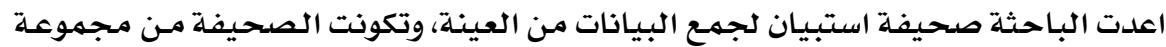

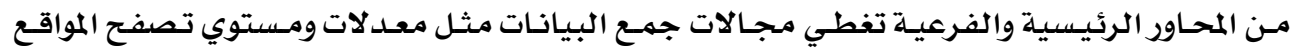

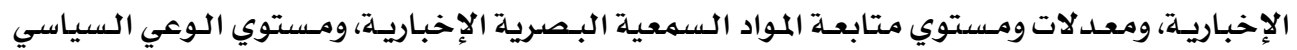

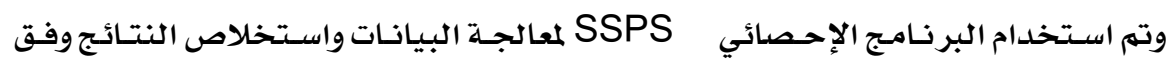
لدي العينة، الضوابط الإحصائية والمتغيرات التي يتهم قياسها. تعرض الباحثة نتائج البحث واختبارات الفروض كالتالي: ا ـمعدلات تصفح الانترنت:

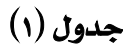

يوضح معدلات تصفح الشباب الجامعي عينة الدراسة للأنترنت

\begin{tabular}{|c|c|c|c|c|}
\hline \multirow{2}{*}{ مستوى الدلالة } & \multirow{2}{*}{ S15 } & \multicolumn{2}{|c|}{ البيان } & \multirow{2}{*}{ مدلات تصفح الانترنت } \\
\hline & & $\%$ & ك & \\
\hline \multirow{6}{*}{$\cdot, \cdot+1$} & \multirow{6}{*}{$971, r \cdot$} & r, ro & 9 & يوم واحد في الاسبوع \\
\hline & & $\$, 0$ & 11 & يومان أسبوعيا \\
\hline & & 1, Yo & $r$ & ثلاثة أيام في الأسبوع \\
\hline & & 9, Yo & rq & أربعة أيام أسبوعيا \\
\hline & & Al, Yo & rYY & أكثر من ذلك. \\
\hline & & $1 .$. & $\{. \cdot$ & الجمــلة \\
\hline
\end{tabular}

ومن الجدول السابق يتضح:

- أن الفئة الأكثر شيوعا هي تلك التي تتصفح أكثر من أربعة أيام يِّ الأسبوع بإجمالي تكرار

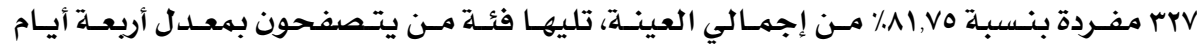

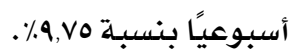

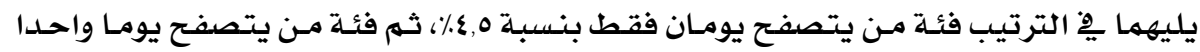

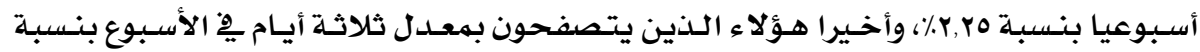

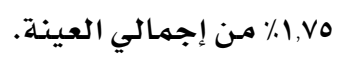

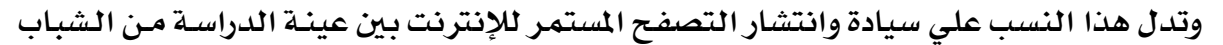

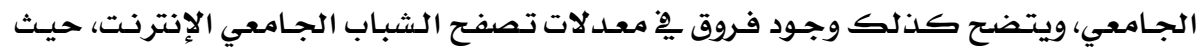

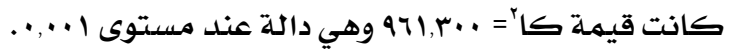


مجلة بحوث التربية النوعية - علدد 0؛ - بناير r.

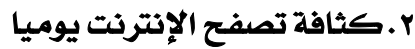

$$
\begin{aligned}
& \text { يوضح الجدول التالي اجمالي وقت تصفح الشباب الجامعي الإنترنت يوميا : } \\
& \text { جدول (r) }
\end{aligned}
$$

\begin{tabular}{|c|c|c|c|c|}
\hline \multirow{2}{*}{ مستوى الدلالة } & \multirow{2}{*}{ قيمة كاr } & \multicolumn{2}{|c|}{ الاستجابة } & \multirow{2}{*}{ جمالي وقت التصفح يوميا } \\
\hline & & $\%$ & ك & \\
\hline \multirow{6}{*}{$\cdot, \cdot \cdot 1$} & \multirow{6}{*}{$19 \%, \cdot$ Yo } & $\S 0, r$ & IAT & أكثر من أربع ساعات يوميا \\
\hline & & 19 & vi & منץ إلي \& ساعات يوميا \\
\hline & & 17,0 & 79 & من ساعة إلي ساعتين يوميا \\
\hline & & 10 & 7. & من ساعتين إلي r ساعات \\
\hline & & $r, \Lambda$ & 10 & أقل من ساعة \\
\hline & & $1 .$. & \&.• & الجمـلة \\
\hline
\end{tabular}

معدل الوقت اليومي لتصفح الإنترنت لدي عينة الدراسة

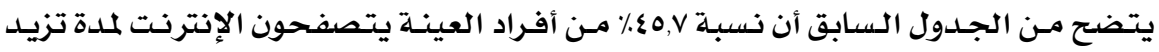

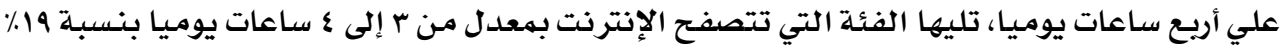

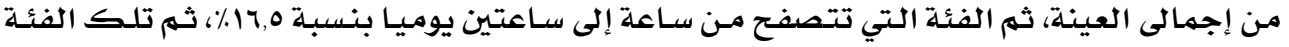

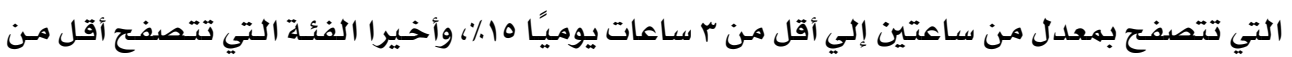

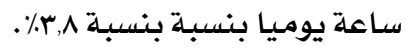

r.أسلوب تصفح عينة الدراسة للأخبار عبر المواقع الاخبارية:

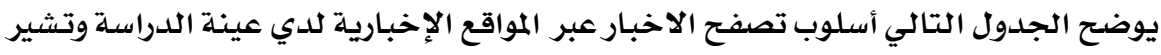

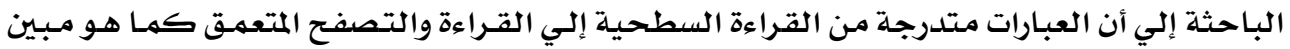

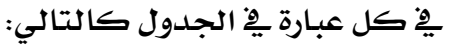




\begin{tabular}{|c|c|c|c|c|c|c|c|c|c|}
\hline \multicolumn{10}{|c|}{ جدول (r) } \\
\hline \multirow{2}{*}{ |الاتجاه|| } & \multirow{2}{*}{ المتوسط } & \multirow{2}{*}{ علداد النقاط } & \multicolumn{2}{|c|}{ ثادرا } & \multicolumn{2}{|c|}{ أحياثا } & \multicolumn{2}{|c|}{ دائما } & \multirow{2}{*}{ |لأسلوب } \\
\hline & & & $\%$ & ك & $\%$ & ك & $\%$ & s & \\
\hline أحيانا & $r, r \wedge$ & 911 & rq & 117 & $1 \varepsilon, Y$ & or & $07, \Lambda$ & rrY & أقرا الخبر وأشاهد الصور المصاحبة له. \\
\hline أحيانا & $r, r_{1}$ & A10 & rr & $\Lambda \Lambda$ & $r \xi, \Lambda$ & $1 r 9$ & $\varepsilon r, r$ & irr & أقرأ الخبر المكتوب فقط \\
\hline أحيانا & $r, 10$ & 109 & $r a, 0$ & 111 & $r q, r$ & 1.0 & $\xi \xi, r$ & irv & أقرا الخبر وأشاهد الفيديو الاخبارى \\
\hline أحيانا & $r, 11$ & A\&r & $r Y, r$ & 1.9 & $r \xi, \Lambda$ & ira & rA & lor & أقرا الخبر بعد سماعه \\
\hline أحيانا & $r, \cdot \cdot$ & $A \cdot 1$ & $\$ 1,0$ & 177 & 17,1 & IV & $\$ 1, \AA$ & $17 r$ & أقرا الخبر في أكثر من موقع. \\
\hline أحيانا & 1,9. & var & $\$ 1, r$ & 170 & rV & $1 \cdot 1$ & $\mathrm{rI}, \Lambda$ & irv & |قرأ الخبر في الموقع وأبحث عنه في القنوات|| \\
\hline أحيانا & $1, Y y$ & $r .0$ & $\varepsilon \eta, r$ & 110 & $r, r$ & iro & $r r, 0$ & 9. & أقرأ عناوين الاخبار فقط \\
\hline أحيانا & $1, Y \varepsilon$ & 790 & $\$ 0$ & iA. & $r q, r$ & 180 & $1 \Lambda, \Lambda$ & ro & اشاهد الفيديو الاخباري فقط \\
\hline 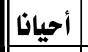 & 1,71 & IVr & or, r & rir & ro,r & 1.1 & $\mathrm{r}, \mathrm{O}$ & $\wedge 7$ & أقرأ مقدمة الخبر قتط \\
\hline 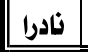 & 1,87 & OAr & $7 r, 0$ & ro. & $r 9,0$ & 111 & $\Lambda$ & rr & أشاهد الصور علي الموقع فقط \\
\hline
\end{tabular}

ومسن بيانـات الجـدول السـابق وبـاسـتخدام معيـار النقـاط وحسـاب المتوسـط المرجح للاتجـاه

السـائد يخ الاستجابات لكل عبـارة يتضح مـا يلي:

- أن أسلوب قـراءة الخبر ومشـاهدة الصور المصاحبـة لـه قد حصل علـي أعلسي معسل مـن النقـاط

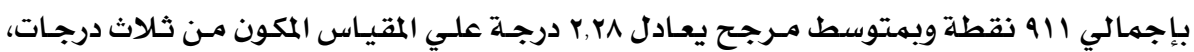

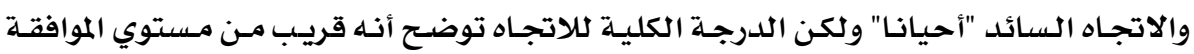
("عץ.ץ" درجـة)، وبالتالي فهو أكثر الأسـاليب شيوعًا فى تصفح المواد الإخباريـة علي الإنترنت. يليه يِ الترتيب الثاني أسلوب قراءة الخبر المكتوب فقط بإجمالي نقـاط 110 نقطة وبمتوسط

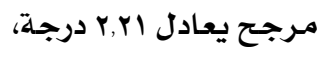

فِّ الترتيب الثالث أسلوب قراءة الأخبـار ومسشاهدة الفيـيو المصاحب إن كان الخبر مـصحوبا بهقطع فيديو، بـاجمالي نقاط قدره 109 نقطة، وبهتوسط مـرجح يعادل ب, بر درجة.

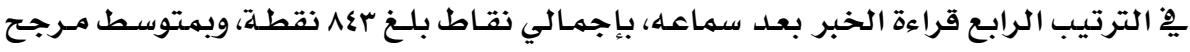

يعادل II, I درجة، وهنا ربها يكون المبحوث قد استهـع للخبر أو عرف عنـه من أوسـاط أخري.

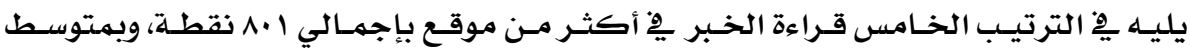
مـرجح يسـاوي درجتان علي المقياس بما يعني " أحيانا" كاتجاه سـائد للإجابـة

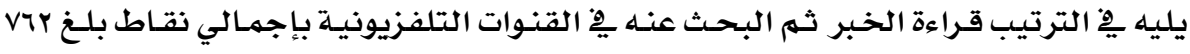

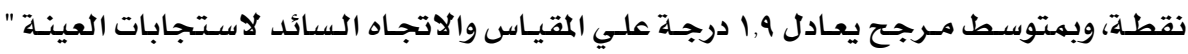
أحيانا" . (1)

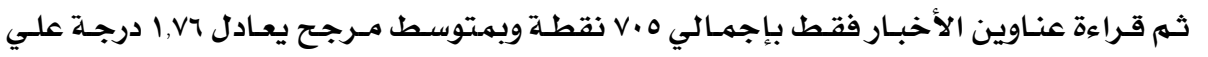
المقياس، والاتجاه السـائد " أحيانا" 


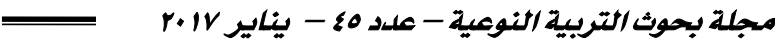

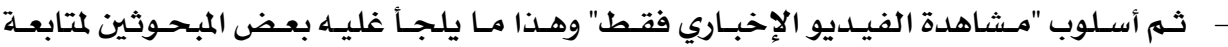

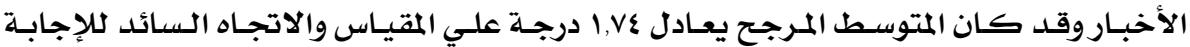
"أحيانا".

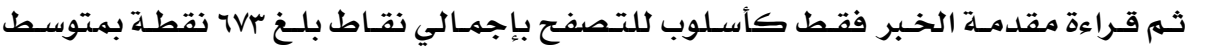

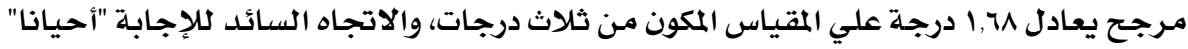

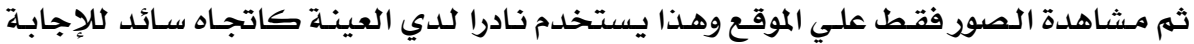

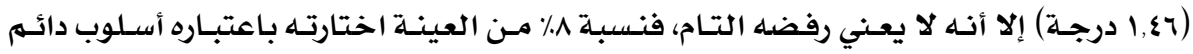

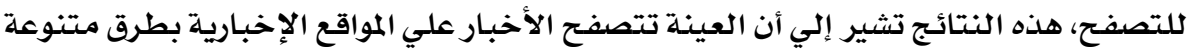

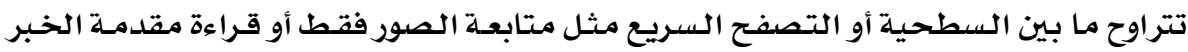

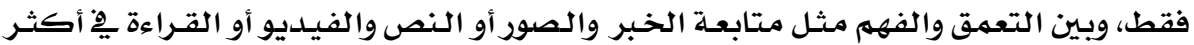

ع. إدراك الشباب الجامعي - عينة الدراسة - لبعض محاور الوعي السياسي:

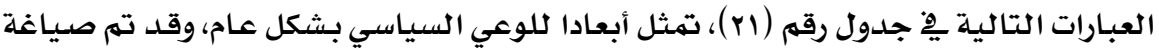

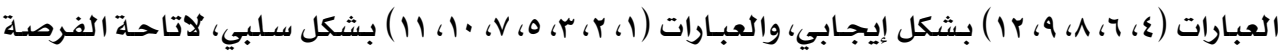

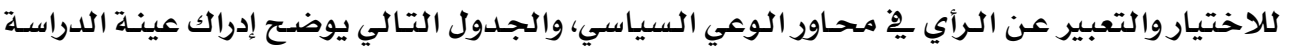
لتلك المحاور ودرجة الموافقة عليها :

جدول (๕)

إدراك عينة الدراسة لبعض محاور الوعي السياسي

\begin{tabular}{|c|c|c|c|c|c|c|c|c|c|}
\hline \multirow{2}{*}{ الاتجاه } & \multirow{2}{*}{ |المرجح } & \multirow{2}{*}{ |النقاط } & \multicolumn{2}{|c|}{ ل أوافق } & \multicolumn{2}{|c|}{ أوافق إلى حد ما } & \multicolumn{2}{|c|}{ 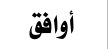 } & \multirow{2}{*}{ 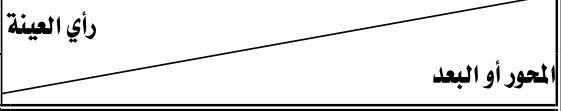 } \\
\hline & & & $\%$ & ك & $\%$ & ك & $\%$ & ك & \\
\hline أوافق & $r, q$. & $117 r$ & $\varepsilon \wedge$ & IAr & $r \xi, 0$ & IrA & iv,o & v. & السياسيوز يبحثوز عن مصالحهم دوز مصالح الجمهور \\
\hline أوافق - & $r, 7 \varepsilon$ & 1.07 & V\&,0 & raA & 10 & 7. & $1 \cdot, 0$ & \&r & اللدولة مسئولة عن انخفاض الوعي السياسي للمواطنين \\
\hline أوافق & r, $\mathfrak{4}$ & 9vฯ & $i r, \Lambda$ & $\Delta 0$ & $\mathrm{rA}, 0$ & $11 \varepsilon$ & ov, $\mathrm{A}$ & ו & لا توجد برامج سياسية واضحة في مصر \\
\hline أوافق - & r, & arr & 10 & 甲. & rv & $1 \cdot 1$ & $\Delta \wedge$ & rrr & اهتم بمتابعة ما يحلدث في المنطقة من تحولات سياسية \\
\hline أوافق & $r, r Y$ & 9รY & 01,1 & $r \cdot r$ & $r r, r$ & irr & 10 & 7. & لا يوجد حزب يستحق أن أسعي للمشاركة فيه \\
\hline أوافق إلى حد ما & r,rr & qrr & 07,1 & rry & 19,1 & va & $r r, 0$ & $9 \xi$ & أود المشاركة في جماعات تخدم المجتمع \\
\hline 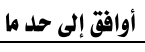 & r, ro & $9 .$. & ro,o & $1 . r$ & rs & 97 & $0 \cdot, 0$ & $1 . r$ & أتجنب المشاركة في الأحزاب حتي لا أهدر وقتي \\
\hline أوافق إلى حد ما & $r, r q$ & $9 . \%$ & 19,8 & VA & $r v, \Lambda$ & 101 & $\xi r, \Lambda$ & $|v|$ & أسعي للتعرف علي السياسة الخارجية المصر بشكل دائم \\
\hline أواقق إلى حد ما & $r, i r$ & A $\leqslant Y$ & ro, 1 & I\&T & $17, \wedge$ & iv & $\{\checkmark, 0$ & 19. & تابعت اخبار الاتتخابات التي أجريت في مصر العام الماضي \\
\hline أوافق إلى حلد ما & 1,94 & rri & $r \varepsilon, 0$ & ira & $r r, \Lambda$ & 90 & $\S 1, \wedge$ & 178 & لا أشارك في أي اتتخابات لان الشاركة بلدون جدوي. \\
\hline ل اوافق & $1,0 \wedge$ & Trr & 19,0 & rA & 19 & vi & 71,0 & rะY & الناخب يهلدروقته بالمشاركة في الاتتخابات \\
\hline لاوافق & 1,89 & 097 & 79 & rVy & ir & or & 11 & Vr & أرغب في الترشح في الاتتخابات مستقبلا \\
\hline
\end{tabular}




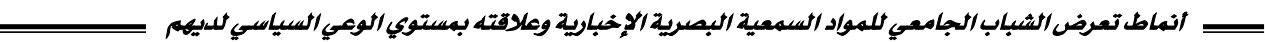

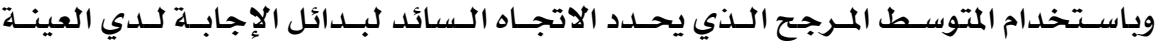

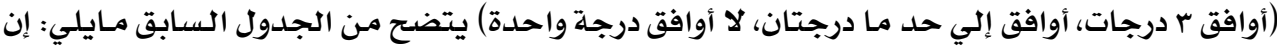

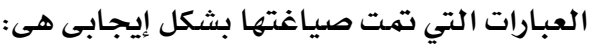

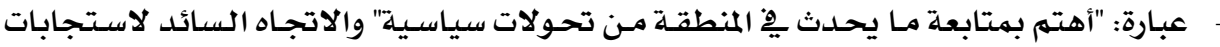

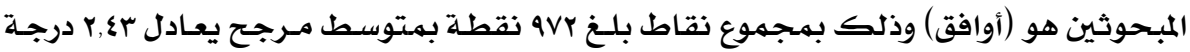
علي المقياس.

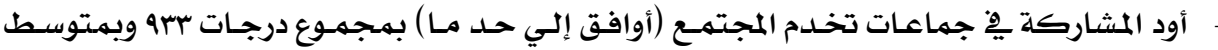

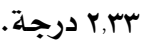

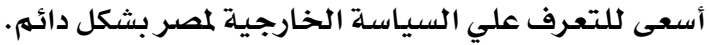

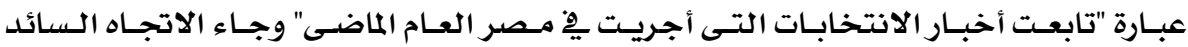

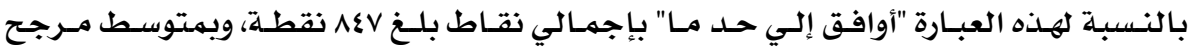

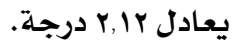

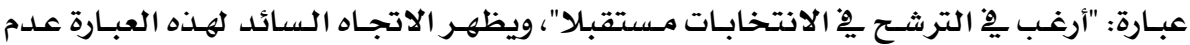

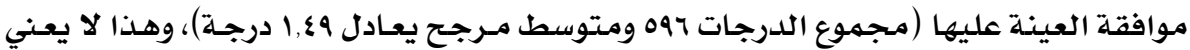

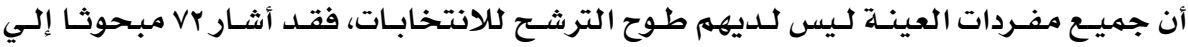

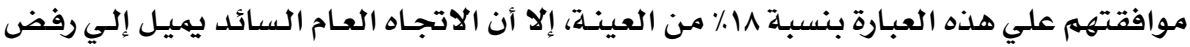

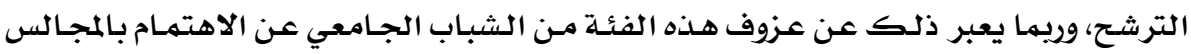

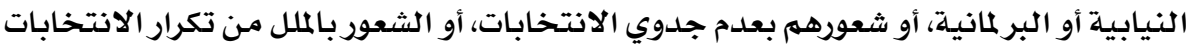

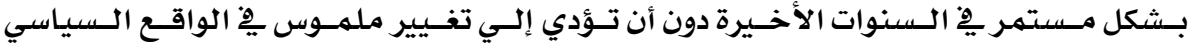
المجتمعي.

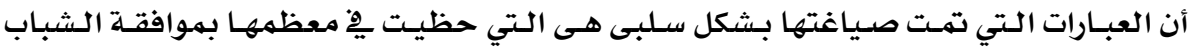

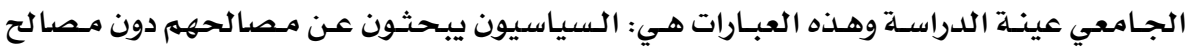

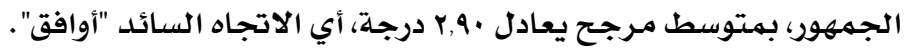

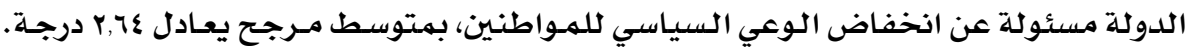

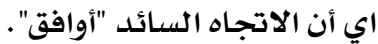

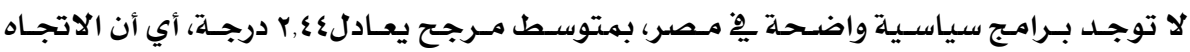
السـائد "أوافق".

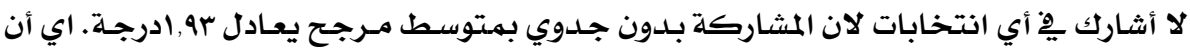
الاتجاه السائد "أوافق إلي حد مالدال

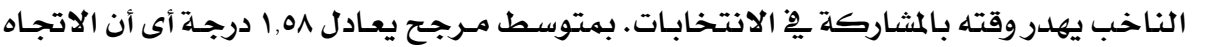

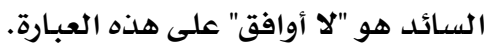

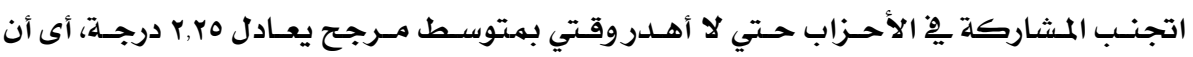

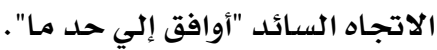


مجلة بحوث التربية النوعية - علد 0؛ - بيناير r.lV

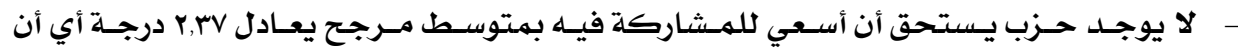
الاتجاه السائد "أوافق".

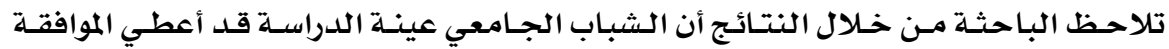

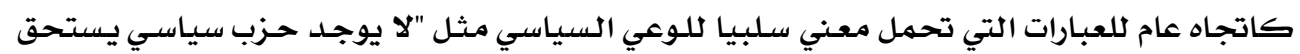

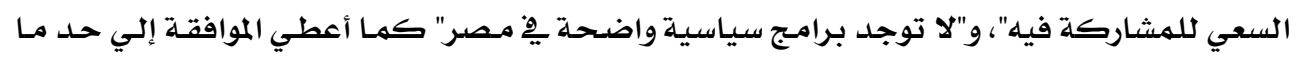

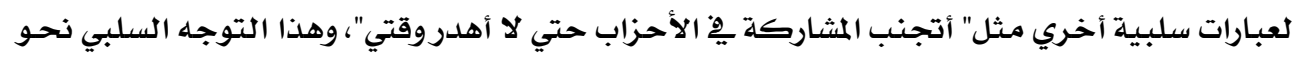

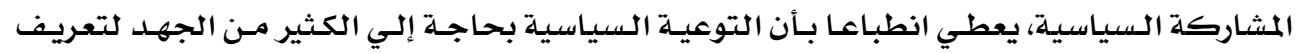

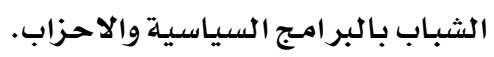

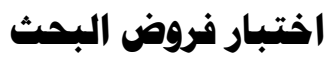

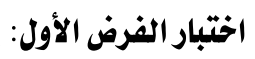
حيث ينص الفرض الأول علي:

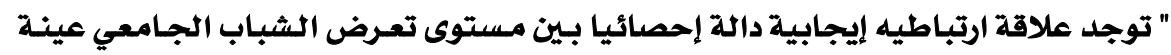

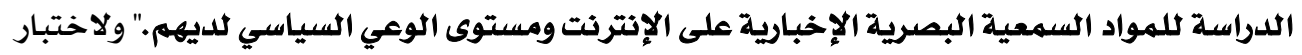
هذا الفرض تم تحديد متغيراته كالتالي:

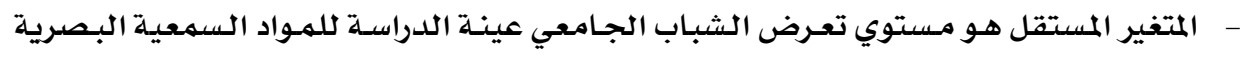

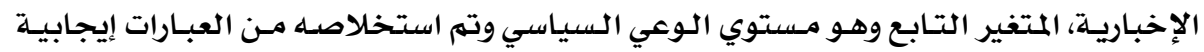

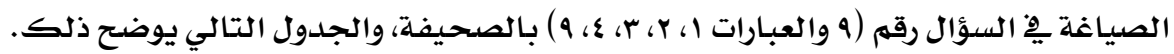

(ه) (هدول)

يوضح العلاقة بين مستوى تعرض عينة الدراسة للمواد السمعية البصرية الإخبارية على الإنترنت

\begin{tabular}{|c|c|c|c|c|c|c|}
\hline مستوى & 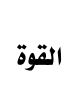 & 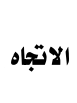 & معامل & الانحراف & المتوسط & المتفير \\
\hline \multirow{2}{*}{$\cdot, \cdot 1$} & \multirow{2}{*}{ 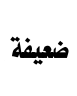 } & \multirow{2}{*}{ طردي } & \multirow{2}{*}{$* *$, rq. } & $1, \cdot r$ & $r, q$ & مستقل مستوى تعرض الشباب الجامعي للمواد السمعية البصرية الإخبارية. \\
\hline & & & & $r, \bullet \varepsilon$ & $1 \cdot, v$ & تابعـ مستوى الوعي السياسي للديهم. \\
\hline
\end{tabular}

يتضح من الجدول السابق بعد حسـاب قيم المتغير المستقل المتمثل ِِّ تعرض عينـة الدراسـة

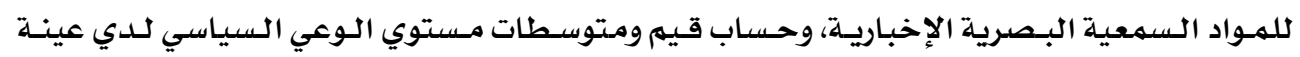

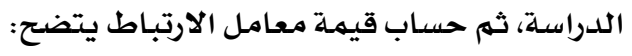

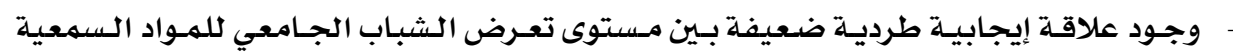

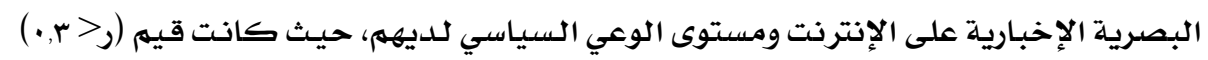
دالة عند مستوى دلالة ال.,.•. 


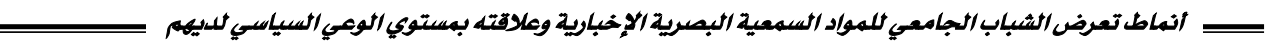

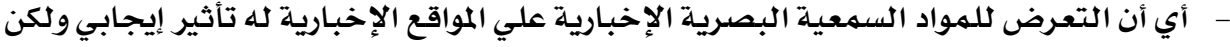

بلدرجة ضعيفة علي مستوي الوعي السياسي لدي الشباب الجامعي عينـة الدراسـة.

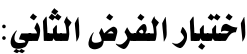
ينص الفرض الثاني علي:

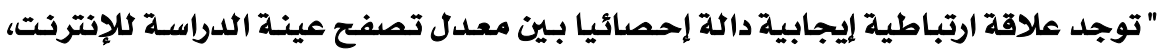

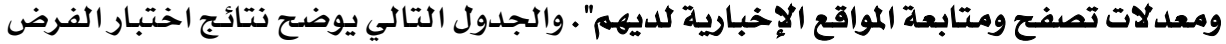

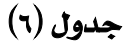

يوضح العلاقة بين معدل تصفح الإنترنت ومعدلات تصفح ومتابعة المواقع الإخبارية

\begin{tabular}{||c|c|c|c|c|c||}
\hline \hline & & & \\
\hline & & & \\
\hline
\end{tabular}

يتضع من الجدول السـابق:

"عـدم وجـود علاقـة ذات دلالـة احصدائية بـين معـدل تصفح الإنترنت ومعـدلات تصففح ومتابعـة

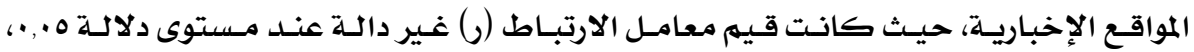
وبالتالي يثبـت عدم صححة الفرض الثالث، بمعني أنه لا توجد علاقة ارتباطيـة، وليس بالضـرورة أن تكون معدلات تصفح الإنترنت الكثيفة ترتبط بتصفح كثيف للهواقع الإخبارية أو العكس.

\section{الخلاصة:}

يعتبر المحتوي الإخباري المرئي المسموع علي المواقع الإخبارية من الظواهر المهمهة التي سـاهمـت فِ تطـوير المحتـوي الإخبـاري علي الإنترنت، وقد تعـرض البـحث الحسادي لتوضـيح العلاقة بـين

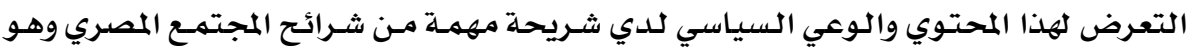
الشباب الجامعي.

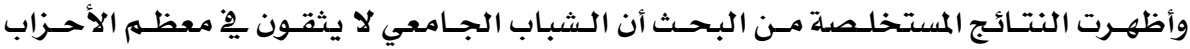
السيـاسيـة وأن هذه الأحزاب ليس لها بـرامـج واضهحة. كما أظهرت النتائج وجود علاقة ارتباطية إيجابيـة دانلة إحصائيا بـين كثافة تعرض الشبـاب الجـامعي للمواقع الإخبارية ومستوي الوعي السياسي لديهم - موضوع هـذا البحثـ- ولكنها علاقة طردية ضعيفة.

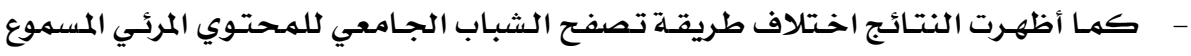
علي الإنترنت وتنوعها، ما بين التصفح السطحي والسريع والذي تدل عليه اجاباتهمر من قراءة العنـاوين فقط، والتصفـح العميـق بقـراءة العنـاوين والـنص ومسشـاهدة المحتـوي المسـموع المرئي للخبر أو للقصة الإخبـارية. 
1. Chung Joo Chung,Yoonjae Nam, Michael A. Stafonone, (2012), Exploring Online News Credibility: The Relative Influence of Traditional and Technological Factors, journal of computer Mediated Communication, Vol. 17, pp: 171-186.

2. James Klurfeld\& Howard Shneider (2014), News Literact: Teaching the internet Generation to make reliable Information Choice, Center for Effective Publication management, Brookings. June 2014.

3. Chung Joo Chung,Yoonjae Nam, Michael A. Stafonone, (2012), Exploring Online News Credibility: The Relative Influence of Traditional and Technological Factors, op cit.

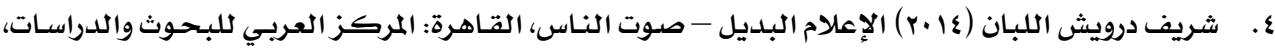

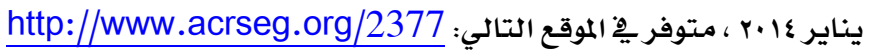

5. Flowrian stofeel et al. (2015), Visual interactive and integrated information on the social media" journal of media research vol. 22 no 1 p: 224-238.

6. Emy Michell et al (2014), News video on the web A Growing, if Uncertain, Part of News.", Pew Research center, available at: www. pewresearch.org

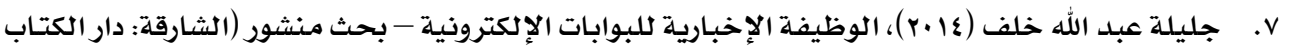

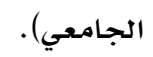

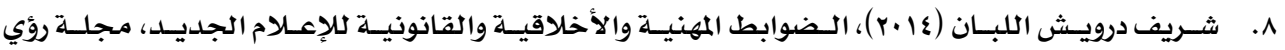

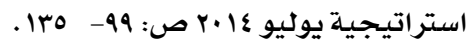

9. Kristen Purcell, (2013), Online Video 2013, Pew Research Center, available at: http://pewinternet.org.

10. Chung Joo Chung, Yoonjae Nam, Michael A. Stafonone, (2012), Exploring Online News Credibility: The Relative Influence of Traditional and Technological Factors" op cit.

11. ${ }^{1}$ ) Pablo J.Boczkowski and Eugenia mitchelstein. "How user take advantage of different forms of internet activity on line news sites: clicking emailing and commerce.

12. Debura s. Chung,\& Mina Tsay,( 2010), Interactive News Presentation and it's Effects on Evaluation Perception: is being "closer" to the news better? ,Paper 
ב أنماط تعرض الشباب الجامعي للهواد السمعية البصرية الإخباريية وعلاقته بهستوي الوعي السياسي لديهم لـ submitted to the newspaper Division of Association for Education in Journalism and Mass communication, ( Boston,5-8 August 2010.

13. Wei Qi, et al. (2010), Integrating Visual, Audio and text Analysis for News Video, available at; http://www.ieee.org/. 